\title{
Spirantization and the Notion of Phonological Strength Relations in Assamese: An Optimality Theoretic Account
}

\author{
Hemanga Dutta \\ The English and Foreign Languages University (EFLU)
}

\begin{abstract}
The paper investigates the problem of phonological strength relations that account for the organization of speech sounds in a specific fashion in the light of spirantization process as attested in the Assamese language, an Indo-Aryan language spoken in the northeastern part of India.

In Assamese aspirated stops $/ \mathrm{p}^{\mathrm{h} /}$ and $/ \mathrm{b}^{\mathrm{h}} /$ are spirantized as [f] and $[\mathrm{v}]$ in word-final position, leaving the unaspirated stops intact. In word-initial and medial positions spirantization is blocked in Assamese. De-aspiration in Assamese does not apply to word final position when no following consonant occurs. In Assamese, coda is de-aspirated when it is followed by an aspirated onset. However
\end{abstract}

\footnotetext{
Hemanga Dutta

Department of Linguistics and Contemporary English, The English and Foreign Language University (EFLU), Hyderabad-500605, India

Phone: 091-9550575673; Email: hemangadutta1@gmail.com
}

Received December 8, 2011; Revised January 20, 2012; Accepted January 31, 2012. 
72 Spirantization and the Notion of Phonological Strength Relations in

the fricatives $/ \mathrm{f} /$ and $/ \mathrm{v} /$ never lose their feature [+asp] despite the fact that both consonants occur in the word-final position or in coda position, being followed by aspirated onset. They turn in to $/ \mathrm{p}^{\mathrm{h}} /$ and $/ \mathrm{b}^{\mathrm{h}} /$ respectively when they are followed by obstruents. Nevertheless, the feature [+asp] is maintained in the onset position which does not undergo alternation. Distribution of Assamese aspirated phonemes at word boundary inform us that only the labial stops spirantize at the word-final position unlike coronal and velar stops which are not susceptible to the process of spirantization.

Keywords: phonological strength, spirantization, de-aspiration

\section{Introduction}

Strength is treated in pertinent literature either as a form of perceptual salience or intrinsic property embedded in a particular segment, as becomes evident in the works of Steriade's (1997) 'Licensing by cue' model, Beckman's (1998) 'Positional faithfulness view,' Kirchner's (1998) 'Integrated models of phonetics and phonology,' and Flemming's (2001) work on 'Phonetic bases of markedness.'

Strength relations can be understood to reflect on asymmetric licensing relations between units in representation. This issue of strength asymmetries in the patterning of segments can be correlated with the process of lenition, which has been described from various perspectives in domain phonological literature, such as feature spreading, sonority promotion, minimization of articulatory effort, and so on. Phonological strength can play a central role in the analysis of phonological patterning not only in the areas of language acquisition, pitch accent patterns and tonal phenomena but also in the well documented cases of segmental asymmetry. Strength relations can be understood to reflect on 
asymmetric licensing relations between units in representation. This issue of strength asymmetries in the patterning of segments can be correlated with the process of lenition, which has been described from various perspectives in the domain phonological literature, such as feature spreading, sonority promotion, minimization of articulatory effort, and so on. This paper revolves around the theme of spirantization that can be subsumed under the rubric of lenition. This research work is designed to address the process of spirantization in Optimality theoretical model with the data drawn from Assamese, an Indo-Aryan language.

In Assamese aspirated stops $/ \mathrm{p}^{\mathrm{h}} /$ and $/ \mathrm{b}^{\mathrm{h}} /$ are spirantized as [f] and $[\mathrm{v}]$ in word-final position, leaving the unaspirated stops intact. In word-initial and medial positions spirantization is blocked in Assamese. De-aspiration in Assamese does not apply to the end of a phrase when no following consonant occurs. In Assamese, coda is de-aspirated when it is followed by an aspirated onset. However the fricatives /f/ and /v/ never lose their feature [+asp] despite the fact that both of these consonants occur in the word final position or in coda position, being followed by aspirated onset. They turn in to $/ \mathrm{p}^{\mathrm{h}} /$ and $/ \mathrm{b}^{\mathrm{h}} /$ respectively when they are followed by obstruents. Nevertheless, the feature [+asp] is maintained in the onset position which does not undergo alternation. Distribution of Assamese aspirated phonemes at word boundary informs us that only the labial stops spirantize at the word final position unlike coronal and velar stops which are not succeptible to the process of spirantization.

\subsection{Lenition from the Perspective of Feature Spreading and Sonority Promotion}

The process of lenition in the domain of phonology has been analysed from various perspectives ranging from feature spreading under autosegmental framework to lenition as sonority promotion 
74 Spirantization and the Notion of Phonological Strength Relations in

treatment, but both the processes failed to offer an explicit and empirically adequate account of unified formal account of lenition or account for the contexts in which lenition normally occurs. Let us first treat the autosegmental treatment to analyse lenition which have been proposed by Selkirk (1982), Harris (1983), Mascaro (1983, 1987), Jacobs \& Wetzels (1988), Cho (1990), and Lombardi (1991). However this treatment of feature spreading is confined to de-gemination, de-buccalisation, and elision as deletion or delinking of phonological material. It fails to provide an explicit account of most typical lenition context, that is the intervocalic position as it suffices to spread the relevant feature from either adjacent vowel and hence the role of the other vowel in conditioning the lenition is unexplained. Next, we can take in to consideration the other perception of lenition as sonority promotion theory which has been proposed by Foley (1977), Clements (1990), Hock (1992), and Lavoie (2001). But this notion also lacks explicit and unified phonetic grounds in explaining the process of lenition. As, for instance, we can consider the sonority scale proposed by Dell \& Elmedlaoui (1985) that is stated below:

(1) stops $>$ voiceless fricatives $>$ voiced fricatives $>$ nasals $>$ liquids $>$ high vowels/glides $>$ low vowels

This sonority scale will lead us to an incorrect assumption that fricatives ought to be able to lenite to nasals. Secondly, sonority account says nothing about the environment and the contexts in which lenition occurs.

\subsection{Lenition and Articulatory Effort}

Kirchner (1998) proposed that lenition is driven by phonetic factors such as minimization of articulatory effort. Thus he proposed explicit and unified phonetic properties in characterizing 
the notion of lenition, in particular the effort cost associated with a given set of articulatory gesture. Language specific lenition constraints emerge, according to Kirchner, from the effort minimization constraint, which is termed as LAZY. It interacts with some lenition blocking constraints within Optimality Theory. The conflict between Lazy and faithfulness constraints can be extended to a variety of lenition phenomena. The type of structural change that occurs in a specific language depends on lenition blocking constraints ranked below: In case of $\mathrm{A}, \mathrm{B}$ occurs/A triggers $\mathrm{B} /$ if $\mathrm{A}$ is present, then $\mathrm{B}$ can be expected.

(i) PRES (length) leads to de-gemination;

(ii) PRES (voice) results in voicing;

(iii) PRES (sonorant) leads to the reduction of an obstruent to an approximant;

(iv) PRES (place feature) results in de-buccalization;

(v) PRES (continuant) results in de-aspirantization in the language.

Lenition, thus assumes a unified characterization, in terms of ranking schema:

(2) LAZY >> lenition blocking constraint

Spirantization as lenition phenomena: It is a process in which a segment turns in to features along with features associated with it. Kirchner argued that the PRES (continuant) will be dominated by LAZY; the resultant output will be spirantization in the language which is demonstrated in Table 1. 
Table 1. Representation of Spirantization Where LAZY $>>$ IDENT (cont)

\begin{tabular}{|c|c|c|}
\hline$/ \mathrm{d} /$ & LAZY & PRES (cont) \\
\hline $\mathrm{d}$ & $* * !$ & \\
\hline$\partial$ & $*$ & $*$ \\
\hline
\end{tabular}

Table 2. Representation of Non Spirantization Where IDENT (cont) $>>$ LAZY

\begin{tabular}{|c|c|c|}
\hline$/ \mathrm{d} /$ & PRES (cont) & LAZY \\
\hline $\mathrm{d}$ & & $* *$ \\
\hline$\partial$ & $* !$ & \\
\hline
\end{tabular}

Spirantization occurs in Table 1 where LAZY dominates PRES (cont); in case of the opposite ranking, as exhibited in Table 2 spirantization is blocked. Such kinds of rankings point out that stops involve higher effort cost than continuants due to the greater distance which the articulator must travel in the former.

Prior to optimality analysis let us see how spirantization process is interpreted within the rubric of autosegmental model. I will also briefly comment on the favourable positions in which spirantization can be assigned cross-linguistically. Rhee (1998) claims that spirantization in most cases occurs in the contexts where target stop is adjacent to a [+cont] segment: prevocalic, postvocalic, or intervocalic position. Nevertheless intervocalic position flanked by both preceding and following [+cont] is found to be the most favourable environment cross-linguistically for a stop to lose its [-cont] and turns in to a segment bearing [+cont].

(3) Examples of Intervocalic Spirantization

a. Kupiya (Christmas \& Christmas 1975) 
[ku:piya] - [ku:Фiya] 'kupia'

[su:pu] - [su: $\phi \mathrm{u}] \quad$ 'winnowing basket'

b. Shina (Rajpurohit 1983)

/babo/ - /baßo/ 'father'

/darbak/ - /darßak/ 'race'

c. Florentine Italian (Kirchner 1996)

/la tavola/ - [la eavola] 'the table'

/e dorme/ - [e $\delta$ rme] 's/he sleeps'

The cases of prevocalic and postvocalic spirantization are also reported in phonological literature. In Boro (Bhat 1968, Bhattacharya 1977), it is found that a voiceless stop spirantizes in prevocalic position and in Nepali (Bandhu \& Dahal 1971) aspirated stops spirantize in postvocalic word final position. Even Tigrinya (Kenstowicz 1982) and Tiberan Hebrew (Malone 1993) are reported to exhibit postvocalic spirantization.

(4) a. Boro (Bhat 1968, Bhattacharya 1977)

$/ \mathrm{p}^{\mathrm{h}^{\mathrm{i}} \mathrm{p}^{\mathrm{h}} \mathrm{a} /}-\left[\phi i \mathrm{p}^{\mathrm{h}} \mathrm{a}\right]$ 'father'

$/ \mathrm{k}^{\mathrm{h}} \mathrm{un} /$ - [xun] 'cotton'

b. Nepali (Bandhu \& Dahal 1971)

$$
\begin{aligned}
& / \mathrm{gəp}^{\mathrm{h}} /-[\mathrm{g} ə \Phi] \\
& / \mathrm{cəb}^{\mathrm{h}} / \mathrm{C}-[\mathrm{cə} \beta]
\end{aligned}
$$

The fact that spirantization always involves the assignment of the feature [+cont] to a stop can be addressed in analogy to the example drawn from Nepali postvocalic word final spirantization, as shown in (4b). 
Figure 1. Typical Autosegmental Analysis: Assimilation to [+cont]

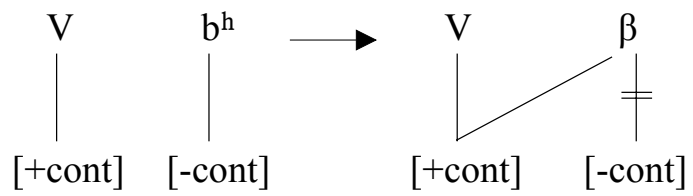

From the above representation in Figure 1, it is quite evident that spirantization is an instance of [ + cont $]$ assimilation. It may not be explicitly addressed in all cases but what one can conclude is that spirantization is an instance of 'ease of articulation.'

The concept of ease of articulation for spirantization is more explicitly and formally expressed in Kirchner (1996, 1997, 1998) embedded in terms of 'articulatory effort minimization.' Kirchner (1998) claims that the phonetic imperative involved in the phonological interpretation of spirantization, minimizes the effort expenditure by means of reducing the magnitude of the articulatory gesture involved in consonant in question. This phonetic imperative in OT framework is classified as LAZY constraint which interacts with the faithfulness constraint to the continuancy that regulates the exactness of the correspondence between the input and the output specifications. A faithfulness constraint that militates against LAZY in the case of spirantization is IDENT (cont).

The constraints can be defined in the following fashion:

(5) LAZY

Minimize articulatory effort.

IDENT (cont)

Correspondent segments in input and output have identical values for continuancy. 
Kirchner (1998) upholds this approach by virtue of the fact that spirants involve less articulatory effort than stops under the definition of effort as 'a mental estimate of the neuromuscular activation levels required to achieve some set of gestures' (Kirchner 1996: 1). Kirchner (ibid.) concludes that an articulatory gesture of greater displacement is more effortful than the one of lesser displacement. Hence, fricatives involve lesser articulatory effort than stops as articulatory displacement for target constriction for fricatives is lesser than that for stops. However, this view of Kirchner contradicts with the observation made by Boersma (1998) according to whom it is not fair to measure the effort merely by articulatory displacement. Boersma (ibid.) claims that it is rather likely that a ballistic movement for a stop, despite greater articulatory displacement, is easier articulatorily than a controlled articulatory movement found in a fricative. Underlying his belief lies is that fricative is more difficult to produce than a stop in articulation, and thus demands more effort than the stops which stands in contradiction with the assumption put forward by Kirchner. Silverman (1997: 5) also gives the view which is in consonance with Boersma when he says "fricatives are marked and presumably involve more effort to properly implement in comparison to stops." Even the data from language acquisition contradict the views put forward by Kirchner. Stops are acquired earlier than fricatives, thereby standing as a setback to provide a positive conclusion that fricatives involve less effort than stops. In Boersma's analysis (1998) articulatory effort is calculated with six primitives: energy, the presence of articulatory gestures, synchronization of gestures, precision, systemic effort, and coordination. Without a proper combination of all these parameters a study concerning articulatory effort expenditure, Kirchner's approach remains elusive.

However, there are two studies conducted by Jacobs (1994) and Hahn (1998) concerning the process of spirantization bear affinities with that of Kirchner with some alternations. In his 
analysis of diachronic French spirantization, Jacob proposed a consonantal markedness constraint called anti association constraint which is stated below:

(6) $* \mathrm{LE} /[+\mathrm{vce},-$ cont $]$

Within LE (LE stands for lenition context), do not associate [+vce, -cont] to a margin after a peak.

The above constraint claims that a voiced stop is disfavoured in lenition context. So spirantization from voiced stop can be represented by ranking $* \mathrm{LE} /[+\mathrm{vce}$, -cont] over IDENT (cont). Similarly Hahn (1998), in his analysis of German final spirantization, has given a constraint *LENI (-cont)] $\sigma$. The dominance of this constraint over IDENT (cont) is responsible for the final spirantization process in German.

(7)

*LENI (-cont)] $\sigma$.

Stops in syllable final position are banned (i.e., do not associate [-cont] in the lenition context).

Both the processes given by Hahn and Jacob are somewhat similar with that of Kirchner although the methodology which they have employed for exhibiting the instance of spirantization is different. However, these approaches fail to make a correlation between spirantization and other closely related lenition processes such as intervocalic voicing and elision.

Prior to the phenomenon of spirantization let us consider the case of coda de-aspiration in Assamese.

\section{Coda De-aspiration in Assamese}

In Assamese aspirated stops $/ \mathrm{p}^{\mathrm{h} /}$ and $/ \mathrm{b}^{\mathrm{h} /}$ are spirantized as [f] 
and $[\mathrm{v}]$ in word-final position, leaving the unaspirated stops intact. Consider the following data:

\begin{tabular}{|c|c|c|}
\hline (8) a. $/ \mathrm{kpp}^{\mathrm{h}} /$ & [kpf] & 'phlegm' \\
\hline b. $/ \mathrm{map}^{\mathrm{h}} /$ & [maf] & 'excuse' \\
\hline c. $/ \operatorname{sap}^{\mathrm{h}} /$ & [saf] & 'clean' \\
\hline d. /bp.nop $/$ & [boInf] & 'ice cream \\
\hline e. $/ 1 a b^{h} /$ & [lav] & 'profit' \\
\hline f. /xulpb $/$ & [xulpv] & 'cheap' \\
\hline g. $/ \mathrm{k}^{\mathrm{h} j o b^{\mathrm{h}} /}$ & [k $\mathrm{k}^{\mathrm{h} j o v]}$ & 'anger' \\
\hline h. /nisp.spb ${ }^{h} /$ & [nisp.IDv] & 'lustreless' \\
\hline
\end{tabular}

Sometimes the coronal stop $/ \mathrm{t}^{\mathrm{h}} /$ spirantizes to dental $/ \mathrm{t}^{\mathrm{h}} /$, as shown in the following data:

(9) a. $/$ zet $^{\mathrm{h}} /\left[\mathrm{zet}^{\mathrm{h}}\right]$ 'the second month of the Assamese year corresponding to May-June'

b. $/$ pith/ $\left[\right.$ pith $\left.^{\text {h }}\right]$ 'place'

However, unlike the labial and coronal stops the velar stops sometimes resist spirantization. But in the speech of some speakers (very rare) the coronal stop spirantizes to velar fricative, which is shown in (10).
(10)
$\begin{array}{lllll}\text { a. } / \mathrm{spk}^{\mathrm{h}} / & {\left[\mathrm{spk}^{\mathrm{h}}\right]} & \text { vs. } & {[\mathrm{spx}]} & \text { 'style' } \\ \text { b. } / \mathrm{d} \varepsilon \mathrm{k}^{\mathrm{h}} / & {\left[\mathrm{d} \varepsilon \mathrm{k}^{\mathrm{h}}\right]} & \text { vs. } & {[\mathrm{d} \varepsilon \mathrm{x}]} & \text { 'to see' }\end{array}$
c. $/ \mathrm{lak}^{\mathrm{h}} / \quad\left[\mathrm{lak}^{\mathrm{h}}\right] \quad$ vs. [lax $] \quad$ 'lacs'

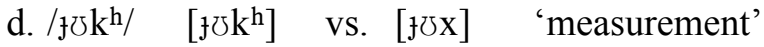
e. $/ x \mho k^{h} / \quad\left[x \mho k^{h}\right]$ vs. $[x \mho x] \quad$ 'happiness'
f. $/ \mathrm{d} \mho \mathrm{k}^{\mathrm{h}} /\left[\mathrm{d} \mho \mathrm{k}^{\mathrm{h}}\right] \quad$ vs. $[\mathrm{d} \mho \mathrm{x}] \quad$ 'sadness'

In word-initial and medial positions spirantization never occurs in Assamese, which is evident from the following data in (11). 
82 Spirantization and the Notion of Phonological Strength Relations in

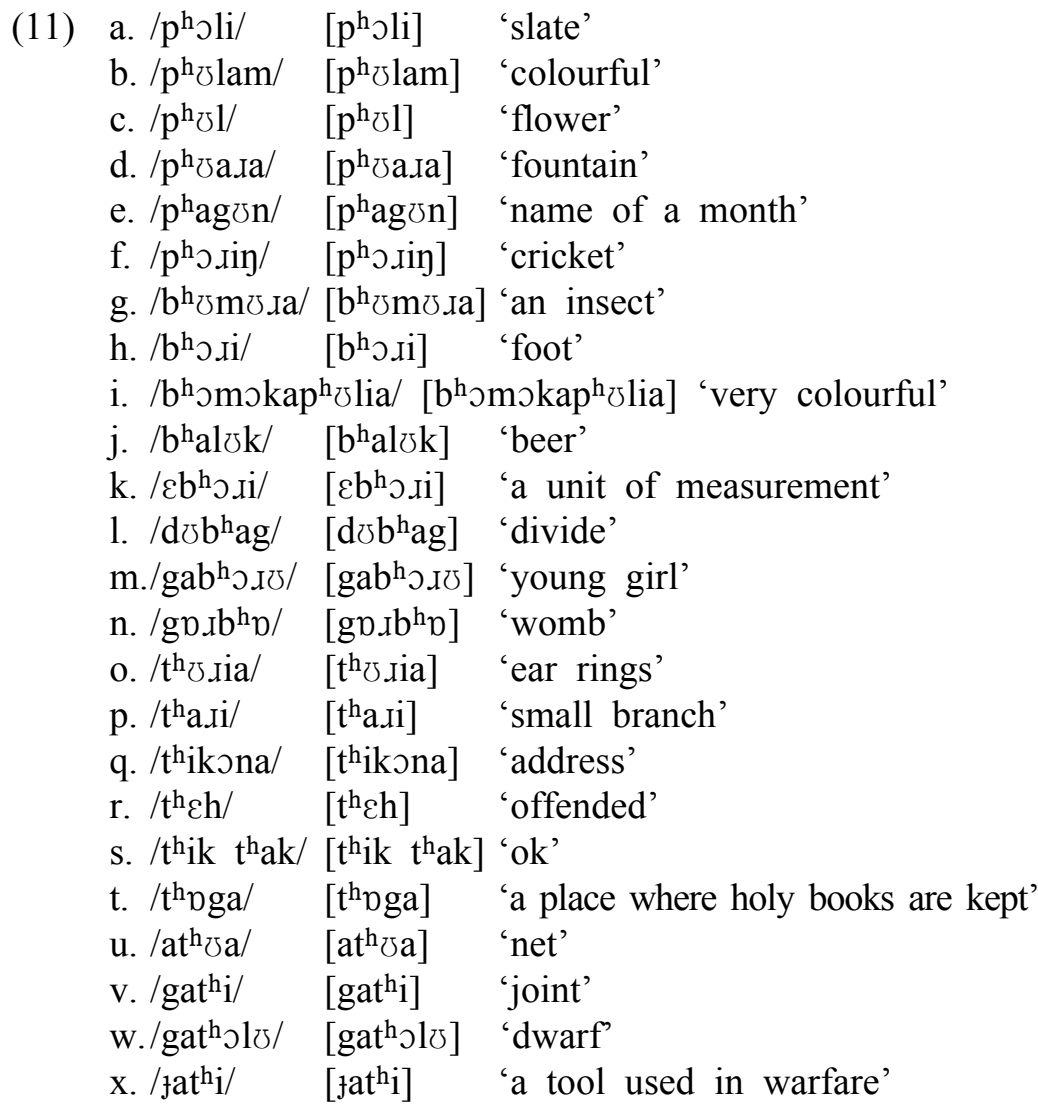

Assamese word final spirantization of the stops $/ \mathrm{p}^{\mathrm{h}} /$ and $/ \mathrm{b}^{\mathrm{h}} /$ into $/ \mathrm{f} /$ and $/ \mathrm{v} /$ can be explained in the framework of Kirchner's model as shown in Table 3 within OT framework: 
Table 3. Spirantization of $/ \mathrm{p}^{\mathrm{h} /}$ in Assamese Where LAZY $>>$ IDENT (cont)

\begin{tabular}{|l|c|c|}
\hline$/ \mathrm{p}^{\mathrm{h}}$ & LAZY & IDENT (cont) \\
\hline $\mathrm{p}^{\mathrm{h}}$ & $* !$ & \\
\hline $\mathrm{f}$ & & $*$ \\
\hline
\end{tabular}

Table 4. Spirantization of $/ \mathrm{b}^{\mathrm{h}} /$ in Assamese Where LAZY $>>$ IDENT (cont)

\begin{tabular}{|c|c|c|}
\hline$/ \mathrm{b}^{\mathrm{h}} /$ & LAZY & IDENT (cont) \\
\hline $\mathrm{b}^{\mathrm{h}}$ & $* !$ & \\
\hline $\mathrm{V}$ & & $*$ \\
\hline
\end{tabular}

The data of spirantization in Assamese can be correlated with the phenomenon of Assamese coda de-aspiration. Consider the following data on coda de-aspiration in Assamese in (12).
a. $\mathrm{kpt}^{\mathrm{h}} \mathrm{k}^{\mathrm{h}} \mathrm{pn}-\mathrm{kpt} \mathrm{k}^{\mathrm{h}} \mathrm{pn}$
'the mat'
b. Int $^{\mathrm{h}} \mathrm{k}^{\mathrm{h}} \mathrm{pn}-$ Int $\mathrm{k}^{\mathrm{h}} \mathrm{pn}$
'the chariot'
c. $\mathrm{ad}^{\mathrm{h}} \mathrm{b}^{\mathrm{h}} \mathrm{ag}-\mathrm{ad} \mathrm{b}^{\mathrm{h}} \mathrm{ag}$
'middle part'
d. at ${ }^{\text {h }} \mathrm{k}^{\mathrm{h}} \mathrm{ila}$ - at $\mathrm{k}^{\mathrm{h}}$ ila
'eight pieces'
e. kat ${ }^{\mathrm{h}} \mathrm{p}^{\mathrm{h}} \mathrm{pta}-\mathrm{kat} \mathrm{p}^{\mathrm{h}} \mathrm{pta}$
'wood splitting'
f. bagh $b^{\text {hal }}$ sk - bag $b^{\text {hal }}$ sk
'tigers and beers'
g. $d \mathrm{k}^{\mathrm{h}} \mathrm{k}^{\mathrm{h}}$ ini $-\mathrm{d} \mho \mathrm{k} \mathrm{k}^{\mathrm{h}}$ ini
'the sadness'
h. boınf bhana - bospb $b^{\text {h }} b^{\text {h}}$ ana
'breaking of the ice'
i. $d \mho k^{h} b^{h} a g-d \mho g b^{h} a g$ 'portion of the sadness'
j. bagh $g^{h_{\mho \eta}}$ - bag $g^{h_{\mho \eta}}$ 'tigers and leopard'
k. boınf $\mathrm{k}^{\mathrm{h}}$ ini - boınp ${ }^{\mathrm{h}} \mathrm{k}^{\mathrm{h}}$ ini 'the ice'
1. kat ${ }^{\mathrm{h}} \mathrm{b}^{\mathrm{h}}$ ana - kat $\mathrm{b}^{\mathrm{h}}$ ana 'breaking of the wood' m.kpf $\mathrm{k}^{\mathrm{h}}$ ini $-\mathrm{kpp}^{\mathrm{h}} \mathrm{k}^{\mathrm{h}}$ ini 'the phlegm'

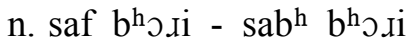
'clean feet'
o. saf $g^{h} \mathrm{D} d-\operatorname{sab}^{\mathrm{h}} \mathrm{g}^{\mathrm{h}} \mathrm{D} d$ 'clean house' 
p. kpf $b^{\text {h}}$ ja $-k p b^{h} b^{h}$ ja $\quad$ 'filled with phlegm'

q. lak ${ }^{\mathrm{h}} \mathrm{k}^{\mathrm{h}}$ elimeli - lak $\mathrm{k}^{\mathrm{h}} \mathrm{elimeli}$ 'dozens of problems'

r. lav $\mathrm{k}^{\mathrm{h}}$ ini - lab ${ }^{\mathrm{h}} \mathrm{k}^{\mathrm{h}}$ ini 'the profit'

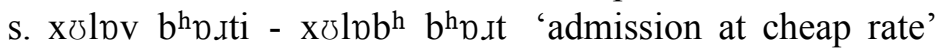

\subsection{Assamese Coda De-aspiration and Autosegmental Representation}

This process of coda de-aspiration can be represented in the following fashion in autosegmental framework:

Figure 2. Representation of Coda De-aspiration in Autosegmental Module

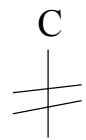

[spread glottis]

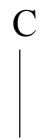

[spread glottis]

Here the $\mathrm{C}$ connected to the node of de-linking line represents the consonant segment occurring in the coda position which is de-aspirated, but the consonant in the onset position retains its feature [spread glottis] thereby enhancing the onset coda asymmetry in phonological literature. But there are some exceptions to this pattern as exhibited by the segments $/ \mathrm{b}^{\mathrm{h} /}$ and $/ \mathrm{p}^{\mathrm{h}} /$.

What is noticeable in this context is that only the labial and velar consonants (optionally) are subject to spirantization. The coronals are never subject to spirantization in word-final position. Secondly, the process of spirantization is blocked when the word final fricatives are followed by the stops. Rather the fricatives lose their feature [+cont] and turn in to [+asp] stops. Thirdly, it is observed that coda de-aspiration in Assamese followed by another aspirated stop in the onset position is blocked in the case of 
spirants.

As, for instance, consider the cases:

(i) $\mathrm{p}^{\mathrm{h}} \rightarrow \mathrm{f} / \mathrm{-}$ \# and when followed by liquids, nasals, and fricatives. However, when it is followed by obstruents it becomes $\mathrm{p}^{\mathrm{h}}$ or $\mathrm{b}^{\mathrm{h}}$.
a. $\mathrm{kpf} \operatorname{spf}-\mathrm{kpp}^{\mathrm{h}} \mathrm{spf}$
b. saf sikun - saf sik
'phlegm and so on'
c. saf zilikil - saf zilikil
'cleanliness'
d. bo.nf xa.a - bo.nf xa.a
'crystal clear'

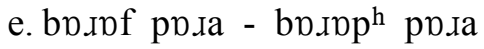
'sweeping of ice'

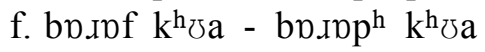
'falling of ice'
g. boınf lva - bo.nof lひa
'to have ice cream'
h. boınf nai - bpınf nai
'to take ice cream'
i. saf zuta - sav zuta
'no ice'
'clean shoes'
j. sof goti - spb goti
'spices'

(ii) $\mathrm{b}^{\mathrm{h}} \rightarrow \mathrm{v} /$ - \# or when followed by fricatives, nasals, and liquids. But it becomes $b^{\text {h }}$ when it is followed by obstruents.
a. lav $\mathrm{sab}^{\mathrm{h}}$ - lav sav
'profit and so on'
b. lav zas - lav zas
'whose profit'
c. lav ximan - lav ximan
'that much profit'
d. lav hða - lav həa
'to make profit'

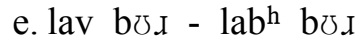
'profits'
f. lav dija $-1 a b^{\mathrm{h}}$ dija
'to give profit'
g. lav gol - lab ${ }^{\mathrm{h}}$ gəl
'to lose profit'
h. lav $\mathrm{gh}_{\mho\lrcorner \mho \mathrm{a}}-\mathrm{lab}^{\mathrm{h}} \mathrm{gh}_{\mho\lrcorner \mho \mathrm{a}}$
'to return profit'
i. lav kpıa - $l a b^{\text {h }}$ kpıa
'to make profit'
j. lav $\mathrm{k}^{\mathrm{h}} \mathrm{ini}-1 \mathrm{ab} \mathrm{h}^{\mathrm{h}} \mathrm{k}^{\mathrm{h}} \mathrm{ini}$
'the profit' 


\subsection{Spirantization, Coda De-aspiration, and OT Constraints}

Autosegmental representation fails to show the process of spirantization in Assamese in an explicit manner. Hence it becomes imperative on our part to analyse this phenomenon with the help of some constraints within Optimality Theory which are addressed below:

(i) Coda Condition (Coda Con): (Kager 1999)

The feature spread glottis [s.g.] is not allowed in the coda position. This constraint prohibits the feature spread glottis [s.g.] from appearing in the coda position.

(ii) *s.g.: (Davis \& Cho 2003)

The feature spread glottis is prohibited. It can be treated as a general markedness constraint militating against the feature [s.g.].

(iii) MAX-s.g.: (Davis \& Cho 2003)

The feature spread glottis [s.g.] in the input must have a corresponding feature [s.g.] in the output. This constraint impliesmaximize input segments in the output in terms of feature spread: one violation for each segment in reagard to feature spread does not appear in the output. The main function of this constraint lies in the fact that it prevents segments to be deleted.

(iv) *OCP-s.g.: (motivated by Goldsmith 1976; 'No identical adjacent autosegments')

This constraint implies: avoid two instances of adjacent [s.g.]. The roots of this constraint can be traced back to the Obligatory Contour Principle, which was originally conceived for tonal 
dissimilation phenomena in Mende and other African tone languages (Leben 1973), and manifested in proper fashion in Goldsmith (1976):

(15) The Obligatory Contour Principle (OCP)

"At the melodic level, adjacent identical elements are prohibited."

In OCP the central notion revolves round 'adjacency' (Myers 1987, Archangeli \& Pulleyblank 1994) which can be categorised in to segment adjacency and tier adjacency. It is the second aspect of adjacency that is instrumental in classical autosegmental theory, as developed by Leben (1973) and Goldsmith (1976), with the pursuit of reducing apparent action at a distance of locality. In the further pursuit of this theory additional representational assumptions became important which include feature geometric separation of feature groups (Clements 1985, Ito 1986, Sagey 1986), morphemically defined tiers (McCarthy \& Prince 1986) and crucial underspecification of certain features (Archangeli \& Pulleyblank 1994, Steriade 1997, Ito \& Mester 1998, and many other works).

OCP is analysed in the framework of Optimality Theory too (Prince \& Smolensky 1993) the main motivation of which lies in understanding the process of OCP, and of featural dissimilation in general. In OT two types of principles have emerged regarding the notion of OCP: one group of phonologists want to maintain the principle in a more or less unchanged form, with diversification in terms of special features and feature groups, as one of rankable and violable constraint that make up an OT grammar and this assumption has been reflected in the works such as the tonal area (Myers 1987) and in segmental phonology (McCarthy \& Prince 1986). Another group is more interested to explore whether it is possible in OT to reduce the OCP to more fundamental notions and restrictions, thereby achieving a deeper level of explanation. 
Ito \& Mester (1998) claim that there is no Obligatory Contour Principle per se: Universal Grammar is not concerned about adjacent identicals qua identicals. Rather, OCP effects arise when markedness constraints are violated more than once.

OCP effects obtain when a given marked type of structure is present more than once within the same local domain.

Multiple violations of one and the same markedness constraint do not simply add up, but interact more strongly, so that a double violation within a given domain is worse than simply the sum of two individual violations. This notion of violation enhancement can get a formal expression by means of self conjunction of constraints (Tesar \& Smolensky 1998).

(v) Local Conjunction of Constraints (LCC)

Kager (1999) claims that under Local Conjunction, two constraints are conjoined as a single composite constraint which is violated if and only if both of its components are violated within the same domain. However this constraint can be traced back to Prince \& Smolensky (1993) according to whom in addition to a set of Con of universal constraints, Universal Grammar contains an operation on Con: local conjunction. In addition to reranking of constraints, local conjunction shows the way in which a line of demarcation can be drawn between individual grammars by making use of combined constraints. The chief motivation of combined constraints lies in allowing grammars to capture a particular type of constraint interaction that cannot be obtained in a theory exclusively built on direct strict domination (Prince \& Smolensky 1993), but is attested in the phonologies of natural languages. We can express this constraint following Ito \& Mester (1998). 
(16) a. Definition:

Local Conjunction is an operation on the constraint set forming composite constraints: Let $\mathrm{C} 1$ and $\mathrm{C} 2$ be members of the constraint set Con. Then their local conjunction $\mathrm{C} 1$ and $\mathrm{C} 2$ is also a member of Con.

b. Interpretation:

The local conjunction $\mathrm{C} 1 \mathrm{C} 2$ is violated if and only if both $* \mathrm{C} 1$ and ${ }^{*} \mathrm{C} 2$ are violated in some domain $\sigma$.

c. Ranking (universal): C1 \& $\mathrm{C} 2>>\mathrm{C} 1$

$\mathrm{C} 1 \& \mathrm{C} 2>\mathrm{C} 2$

$\mathrm{C} 1 \& \mathrm{C} 2$ is potentially active when there is some constraint $\mathrm{C} \alpha$ (typically, but not necessarily a faithfulness constraint militating against violations of $\mathrm{C} 1$ and/or $\mathrm{C} 2$ ) ranked between the conjoined constraint and at least one of the two basic constraints, as shown below:

d. $\mathrm{C} 1 \& \delta \mathrm{C} 2>>\mathrm{C} \alpha>>\mathrm{C} 1$ or, $\mathrm{C} 1 \& \mathrm{C} 2>\mathrm{C} \alpha>\mathrm{C} 2$

The constraint of Local Conjunction can better be analysed in the constraint based analysis of German Coda Devoicing, which implies that voiced obstruents are marked elements, and syllable codas are marked positions. The phonology of German permits both, thereby emphasizing on the faithful parsing of the input and what is ruled out is the marked in the marked position: a voiced obstruent as a coda. Following Ito \& Mester (1998) below is given the constraint conjunctive analysis of German final devoicing where the two individual constraints involved are the syllable structure constraint NOCODA and the segmental markedness constraint against voiced obstruents, which is termed Voiced Obstruent Prohibition (VOP): 
90 Spirantization and the Notion of Phonological Strength Relations in

(17)

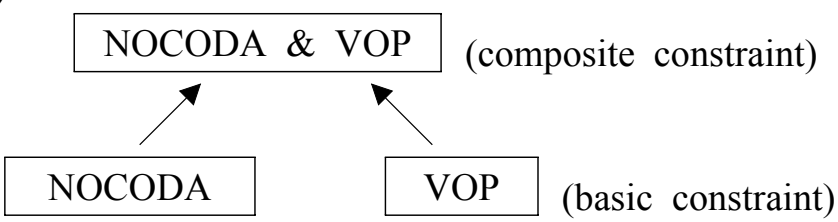

The additional factor which is responsible for coda devoicing, while at the same time limiting it to coda position, is the faithfulness ranking: the position of IDENT[F] below the conjoined constraint NOCODA \& VOP and above the simple feature markedness constraint VOP.

Figure 3. Representation of Constraint Conjunctive Analysis of German Final Devoicing

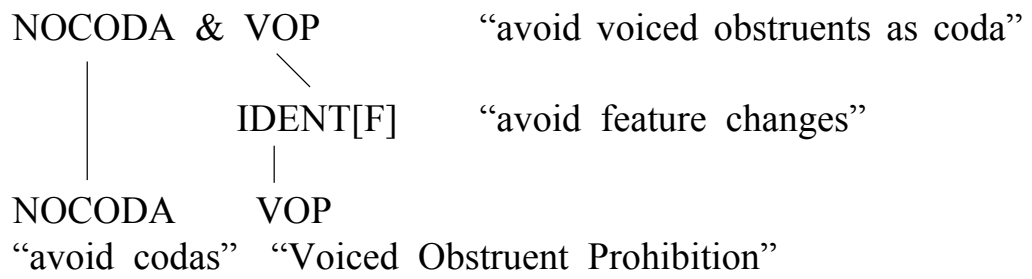

Indeed, the chief motivation for Local Conjunction of constraints resides in chain shift (Kirchner 1996). According to Kager (1999) a chain shift implies a situation in which sounds are promoted or demoted stepwise along some scale in some context. The chain shift crucially does not result in neutralization, since each input occupies one step precisely. This can be represented in the following schemata:

(18) $\mathrm{A} \rightarrow \mathrm{B}$ and $\mathrm{B} \rightarrow \mathrm{C}$, but not $* \mathrm{~A} \rightarrow \mathrm{C}$ 


\subsection{Assamese Data on Spirantization and the OT Constraints: An Analysis}

Table 5. Assamese Data on Spirantization

\begin{tabular}{|c|c|c|c|c|c|c|}
\hline $\begin{array}{c}\text { Final } \\
\text { consonant }\end{array}$ & $\begin{array}{c}\text { Voiceless } \\
\text { unaspirated } \\
\text { stop }\end{array}$ & $\begin{array}{c}\text { Voiced } \\
\text { unaspirated } \\
\text { stop }\end{array}$ & $\begin{array}{l}\text { Voiceless } \\
\text { aspirated } \\
\text { stop }\end{array}$ & $\begin{array}{l}\text { Voiced } \\
\text { aspirated } \\
\text { stop }\end{array}$ & $\begin{array}{c}\text { Voiceless } \\
\text { aspirate }\end{array}$ & $\begin{array}{l}\text { Voiced } \\
\text { aspirate }\end{array}$ \\
\hline$f=p^{h}$ & $\mathrm{p}^{\mathrm{h}} \mathrm{k}$ & $b^{h} g$ & $\mathrm{p}^{\mathrm{h}} \mathrm{k}^{\mathrm{h}}$ & $b^{h} g^{h}$ & $\mathrm{f} \mathrm{s}$ & $\mathrm{V} \mathrm{Z}$ \\
\hline$t^{h}$ & $\mathrm{t}^{\mathrm{h}} \mathrm{k}$ & $d^{h} g$ & $\mathrm{t} \mathrm{k}^{\mathrm{h}}$ & $d g^{h}$ & $\mathrm{t} \mathrm{s}$ & $\mathrm{d} \mathrm{z}$ \\
\hline $\mathrm{k}^{\mathrm{h}}$ & $\mathrm{k}^{\mathrm{h}} \mathrm{k}$ & $g^{h} g$ & $\mathrm{k} \mathrm{k}^{\mathrm{h}}$ & $\mathrm{g} \mathrm{g}^{\mathrm{h}}$ & $\mathrm{k} \mathrm{s}$ & $\mathrm{g} \mathrm{Z}$ \\
\hline $\mathrm{v}=\mathrm{b}^{\mathrm{h}}$ & $b^{h} k$ & $b^{h} g$ & $b^{h} k^{h}$ & $b^{h} g^{h}$ & $\mathrm{~V} \mathrm{~S}$ & $\mathrm{~V} \mathrm{Z}$ \\
\hline$d^{h}$ & $d^{h} k$ & $d^{h} g$ & $\mathrm{~d} \mathrm{k}^{\mathrm{h}}$ & $\mathrm{d} \mathrm{g}^{\mathrm{h}}$ & d s & $\mathrm{d} \mathrm{z}$ \\
\hline $\mathrm{g}^{\mathrm{h}}$ & $\mathrm{g}^{\mathrm{h}} \mathrm{k}$ & $\mathrm{g}^{\mathrm{h}} \mathrm{g}$ & $\mathrm{g} \mathrm{k}^{\mathrm{h}}$ & $\mathrm{g} \mathrm{g}^{\mathrm{h}}$ & g s & g z \\
\hline $\mathrm{P}$ & $\mathrm{p} \mathrm{k}$ & b g & $\mathrm{p} \mathrm{k}^{\mathrm{h}}$ & b g $g^{h}$ & $\mathrm{p} \mathrm{s}$ & $\mathrm{b} \mathrm{z}$ \\
\hline $\mathrm{t}$ & $\mathrm{t} \mathrm{k}$ & d g & $\mathrm{t} \mathrm{k}^{\mathrm{h}}$ & $d g^{h}$ & $\mathrm{ts}$ & $\mathrm{d} z$ \\
\hline $\mathrm{k}$ & $\mathrm{k} \mathrm{k}$ & g $g$ & $\mathrm{k} \mathrm{k}^{\mathrm{h}}$ & $g g^{h}$ & $\mathrm{k} \mathrm{s}$ & $\mathrm{g} \mathrm{z}$ \\
\hline $\mathrm{b}$ & b k & b g & $\mathrm{b} \mathrm{k}^{\mathrm{h}}$ & $b g^{h}$ & b s & $\mathrm{b} \mathrm{z}$ \\
\hline$d$ & $\mathrm{~d} \mathrm{k}$ & d g & $\mathrm{d} \mathrm{k}^{\mathrm{h}}$ & $d g^{h}$ & $\mathrm{ds}$ & $\mathrm{d} \mathrm{z}$ \\
\hline $\mathrm{g}$ & $\mathrm{g} \mathrm{k}$ & $\mathrm{g} g$ & $\mathrm{~g} \mathrm{k}^{\mathrm{h}}$ & $\mathrm{g} \mathrm{g}^{\mathrm{h}}$ & g s & $\mathrm{g} \mathrm{z}$ \\
\hline
\end{tabular}

The above table represents the distribution of Assamese aspirated phonemes at word boundary where it is observed that only the labial stops spirantize at the word final position unlike coronal and velar stops which are not susceptible to the process of spirantization. This can be represented within OT constraints following Kirchner (1998) as has been shown in section.

The fact the coda de-aspiration in fast tempo in Assamese following another aspirated stop in the following onset position can be analysed from the perspective of Obligatory Contour Principle, that is, identical segments do not occur in adjacent 
92 Spirantization and the Notion of Phonological Strength Relations in

position. Consider the following example:

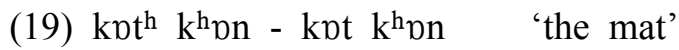

In the above example the coda is de-aspirated when it is followed by another aspirated stop in the onset position. It implies that two consecutive aspirated stops cannot occur. Here, *OCP-s.g. is higher ranked than MAX-s.g., Coda Con and *s.g. as evident from the following table:

(20) $/ \mathrm{kpt}^{\mathrm{h}} \mathrm{k}^{\mathrm{h}} \mathrm{pn} /-\left[\mathrm{kpt} \mathrm{k} \mathrm{k}^{\mathrm{h}}\right]$ 'the mat'

Table 6. Representation of Coda De-aspiration in $/ \mathrm{knt}^{\mathrm{h}} \mathrm{k}^{\mathrm{h}} \mathrm{pn} /$ Where *OCP-s.g. > MAX-s.g. > Coda Con $>*$ s.g.

\begin{tabular}{|c|c|c|c|c|}
\hline $\mathrm{knt}^{\mathrm{h}} \mathrm{k}^{\mathrm{h}} \mathrm{pn} /--/$ & $*$ OCP-s.g. & MAX-s.g. & Coda Con & $*$ s.g. \\
\hline (a) $/ \mathrm{knt}^{\mathrm{h}} \cdot \mathrm{k}^{\mathrm{h}} \mathrm{pn} /$ & $* !$ & & $*$ & $* * *$ \\
\hline (b) $\mathrm{kpt}^{\mathrm{h}} \mathrm{k}^{\mathrm{h}} \mathrm{pn}$ & & $*$ & & $* *$ \\
\hline (c) $\mathrm{knt}^{\mathrm{h}} . \mathrm{knn}$ & & $*$ & $* !$ & $* *$ \\
\hline
\end{tabular}

Here from this table we get the winning candidate (b) which, in addition to violating lower ranked *s.g., violates MAX-s.g. and it is higher ranked than Coda Con and *s.g. In this table the candidate (a) violates *OCP-s.g. which outranks all other constraints. On the other hand candidate (b) and candidate (c) violate *s.g. twice and MAX-s.g. once yet candidate (b) appears as winner. It is because candidate (c), in addition to violating *s.g. and MAX-s.g., violates Coda Con. So in this instance of coda de-aspiration the ranking schemata can be represented in the following way:

(21) Constraint ranking: *OCP-s.g. >> MAX-s.g. >> Coda Con, $*_{\text {s.g. }}$ 
But this OCP constraint is violated in case of spirants following by another aspirated stops in onset position. As, for instance, the fricatives $/ \mathrm{f} /$ and $/ \mathrm{v} /$ never lose their feature [+asp] despite the fact that both of these consonants occur in the word final position or in coda position, being followed by aspirated onset. They turn in to $/ \mathrm{p}^{\mathrm{h}} /$ and $/ \mathrm{b}^{\mathrm{h}} /$ respectively when they are followed by obstruents. Nevertheless, the feature [+asp] is maintained in the onset position which is never susceptible to change. An analysis is given below in the light of the example given below:

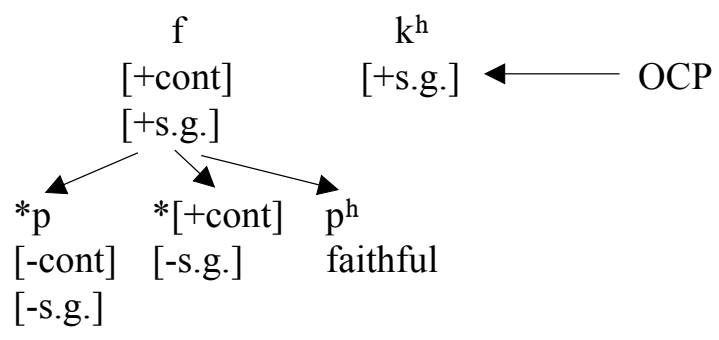

This phenomenon can be observed by using OT theoretical model by ranking constraints. In the above example it is evident that the continuancy is a feature which is not susceptible to OCP constraint whereas the stops having the features [-cont] lose their feature [s.g.] under OCP when it is followed by another aspirated stop in onset position. In the above interpretation of $/ f /$ three possible outputs can be expected: segments having the feature ([-cont][-s.g.]) which is violable under faithfulness constraint. The segments having the features ([+cont][-s.g.]) is not phonetically plausible. It is ruled out by the phonetic constraint */+cont, -s.g./. So it assumes the feature [+asp] in spite of occurring in the coda position thereby being faithful to the feature continuancy in input. In contrast, in Assamese the segments having [-cont] and [+s.g.] 
94 Spirantization and the Notion of Phonological Strength Relations in

undergo transformation and lose their [+asp] feature when they are followed by another aspirated stop. This issue can also be analysed from the perspective of derivational steps. In the case of coda de-aspiration in Assamese the final stop undergoes only one transformation. It implies that de-aspiration occurs under the contact of the following aspirated stop. But in case of spirants in the final coda position, we do not see a single derivational step involved in the process of de-aspiration. The feature [+cont] blocks the spirants to lose the feature [+s.g.] although they are bound to lose [+cont]. It is evident from the following diagrammatic representation:

Figure 4. Representation of Steps Involved in the Transformation of Features

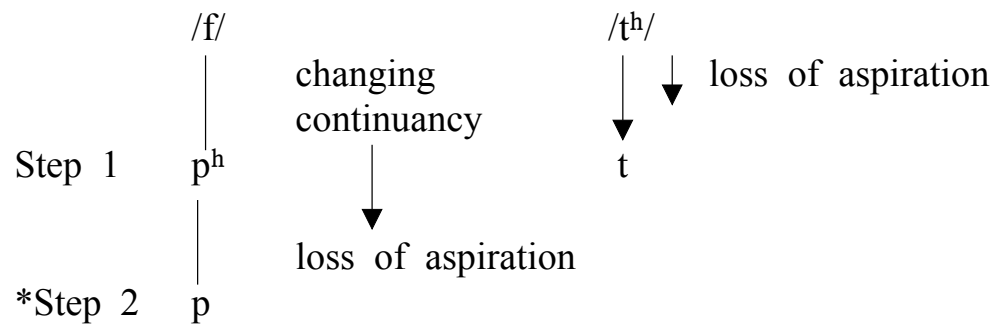

In order to authenticate this notion I am going to take in to consideration some OT constraints that I have discussed in the previous section. Consider the following example:

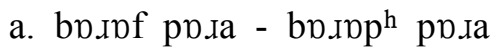
'falling of ice'
b. bo.nf $\mathrm{k}^{\mathrm{h}_{\mho \mathrm{a}}}-\mathrm{bDInp}^{\mathrm{h}} \mathrm{k}^{\mathrm{h}_{\mho \mathrm{a}}}$ 'to have ice cream'

Now consider the input $/ \mathrm{f} \mathrm{k}^{\mathrm{h}} /$. 
Table 7. OT Analysis of the Assamese Input /f $\mathrm{k}^{\mathrm{h} /}$

\begin{tabular}{|c|c|c|c|c|c|}
\hline Input & $\begin{array}{c}*[+ \text { continuant] } \\
{[- \text {-continuant] }}\end{array}$ & $\begin{array}{c}\text { Faith[s.g.] \& } \\
\text { Faith[cont] }\end{array}$ & $*$ OCP-s.g. & $*$ [s.g.] & Coda Con \\
\hline (a) $\mathrm{f} \mathrm{k}^{\mathrm{h}}$ & $!^{*}$ & & $*$ & $*$ & $*$ \\
\hline (b) $\mathrm{p}^{\mathrm{h}} \mathrm{k}^{\mathrm{h}}$ & & & $*$ & & $*$ \\
\hline (c) $\mathrm{pk}^{\mathrm{h}}$ & & $* !$ & & $*$ & \\
\hline (d) $\mathrm{p}^{\mathrm{h}} \mathrm{k}$ & & $* !$ & & $*$ & $*$ \\
\hline
\end{tabular}

Here, in this OT framework, the candidate (b) appears as the optimal candidate as the constraints violated by (b) are lower ranked in Assamese.

The candidate (a) violates $*[+$ continuant $][-$ continuant $]$, that is, a consonant which is [+continuant] can not be followed by another consonant which is [-continuant]. In addition it violates the constraint $*$ OCP-s.g., that prohibits identical adjacent segments. It violates $*$ [s.g.], that is a markedness constraint militating against the feature spread glottis, and Coda Con, which implies that the feature spread glottis is not allowed in the coda position. The candidate (c) violates Local Conjunction Constraint, that is Faith[s.g.] \& Faith[cont], that implies that the output must be faithful in terms of feature spread glottis and continuancy to its input counterpart. This Local Conjunction is violated if both ${ }^{*} \mathrm{C} 1$ and ${ }^{*} \mathrm{C} 2$ are violated in a local domain. The candidate (c) violates LCC by virtue of violating not only Faith[s.g.] but also Faith[cont]. Candidate (d) is ruled out on the ground of violating Faith[s.g.] \& Faith[cont] apart from *[s.g.] and Coda Con.

The fact that spirantization of labial fricatives at word-final position in Assamese is blocked when followed by stops can be thus represented through the reranking of the constraints within OT framework.

The ranking of the constraints held responsible for this process can be depicted in the following fashion: 
(24)

$$
\begin{aligned}
& *[+ \text { cont }][- \text { cont }]>>\text { Faith[s.g. }] \& \text { Faith }[\text { cont }]>>\text { OCP-s.g. } \\
& >>\text { *s.g. }>>\text { Coda Con }
\end{aligned}
$$

\section{Conclusions}

Spirantization is treated in this paper as a process of lenition which is detected in the word-final position. Similarly to coda de-aspiartion, spirantization occurs in the coda or the word-final position and thereby supports the claim of positional asymmetry or positional privilege. Spirantization is never found in word-initial and medial position, as evident from the data on Assamese. However cross linguistically word medial position is found to be the suitable place for spirantization to occur. Hence it must be argued that language-specific phonotactics is bound to play a crucial role in the patterning of speech sounds. We have demonstrated that the fricatives /f/ and /v/ never lose their feature [+s.g.] despite the fact that both consonants occur in the word-final position or in coda position, followed by aspirated onset. They turn into $/ \mathrm{p}^{\mathrm{h}} /$ and $/ \mathrm{b}^{\mathrm{h}} /$ respectively when followed by obstruents. Nevertheless, the feature [+s.g.] is maintained in the onset position which does not undergo alternation. The distribution of Assamese aspirated phonemes at word boundary reveals that only the labial stops spirantize at the word-final position unlike coronal and velar stops which are not susceptible to the process of spirantization. Hence the ranking of the constraints responsible for spirantization in Assamese is:

$$
\begin{aligned}
& *[+ \text { cont }][\text {-cont }]>\text { Faith[s.g. }] \& \text { Faith }[\text { cont }]>>\text { *OCP-s.g. }>> \\
& * \text { s.g. }>>\text { Coda Con }
\end{aligned}
$$




\section{References}

Archangeli, D. \& D. Pulleyblank. 1994. Grounded Phonology. Cambridge, MA: MIT Press.

Bandhu, C. \& B. Dahal. 1971. Nepali Segmental Phonology. Kirtipur: Tribhuvan University Press.

Beckman, J. 1998. Positional Faithfulness. Ph.D Dissertation. University of Massachusetts, Amherst.

Bhat, D. 1968. Boro Vocabulary: With a Grammatical Sketch.

Poona: Deccan College, Postgraduate \& Research Institute.

Bhattacharya, P. 1977. A Descriptive Analysis of the Boro Language. Gauhati: Gauhati University Press.

Boersma, P. 1998. Functional Phonology. Ph.D Dissertation. University of Amsterdam.

Cho, Y. 1990. Parameters of Consonantal Assimilation. Ph.D Dissertation. Stanford University.

Christmas, R. \& J. Christmas. 1975. Kupia Phonemic Summary. Kathmandu: Tribhuvan University Press.

Clements, G. 1985. The Geometry of Phonological Features. In C.

Ewen \& E. Kaisse (eds.), Phonology Yearbook II 225-252.

Cambridge: Cambridge University Press. . 1990. The Role of the Sonority Cycle in Core Syllabification.

In J. Kingston \& M. Beckman (eds.), Laboratory Phonology I:

Between the Grammar and Physics of Speech 283-333. Cambridge: Cambridge University Press.

Davis, S. \& M-H. Cho. 2003. The Distribution of Aspirated Stops and $/ \mathrm{h} /$ in American English and Korean: An Alignment Approach with Typological Implications. Linguistics 41, 607-652. Dell, F. \& M. Elmedlaoui. 1985. Syllabic Consonants and Syllabification in Imdlawn Tashlhiyt Berber. Journal of African Languages and Linguisitics 7, 105-130.

Flemming, E. 2001. Contrast and Perceptual Distinctiveness. In B. Hayes et al. (eds.), The Phonetic Bases of Markedness. 
Cambridge: Cambridge University Press.

Foley, J. 1977. Foundations of Theoretical Phonology. Cambridge: Cambridge University Press.

Goldsmith, J. 1976. Autosegmental Phonology. Ph.D Dissertation. MIT.

Hahn, A. 1998. German Final Devoicing in Optimality Theory. Ms., University of Paderborn [ROA 241-0198].

Harris, J. 1983. Syllable Structure and Stress in Spanish: A Nonlinear Analysis. Cambridge, MA: MIT Press.

Hock, H. 1992. Initial Strengthening. In W. Dressler et al. (eds.), Phonologica 1988: Proceedings of the $6^{\text {th }}$ International Phonology Meeting 101-110. Cambridge: Cambridge University Press.

Ito, J. 1986. Syllable Theory in Prosodic Phonology. Ph.D Dissertation. University of Massachusetts, Amherst.

Ito, J. \& R. Mester. 1998. Markedness and Word Structure: OCP Effects in Japanese. Ms., University of California, Santa Cruz. Jacobs, H. 1994. Lenition and Optimality Theory. Ms., Nijmegen University \& Free University [ROA 127-0496].

Jacobs, H. \& L. Wetzels. 1988. Early French Lenition: A Formal Account of an Integrated Sound Change. London: Garland Press. Kager, R. 1999. Optimality Theory. Cambridge: Cambridge University Press.

Kenstowicz, M. 1982. Gemination and Spirantization in Tigrinya.

Studies in the Linguistic Sciences 12.1, 103-122.

Kirchner, R. 1996. Synchronic Chain Shifts in Optimality Theory, Linguistic Inquiry 27.2, 341-350.

. 1997. Contrastiveness and Faithfulness. Phonology 14.1, 83-111.

. 1998. An Effort Based Approach to Consonant Lenition.

Ph.D Dissertation. University of California, Los Angeles.

Lavoie, L. 2001. Consonant Strength: Phonological Patterns and

Phonetic Manifestations. New York: Garland Press.

Leben, W. 1973. Suprasegmental Phonology. Bloomington, IN: 
Indiana University Linguisitc Club.

Lombardi, L. 1991. Laryngeal Features and Laryngeal Neutralization. Ph.D Dissertation. University of Massachusetts, Amherst.

Malone, J. 1993. Tiberian Hebrew Phonology. Winona Lake, IN: Eisenbraus.

Mascaro, J. 1983. Continuant Spreading in Basque, Catalan, and Spanish. In M. Aronoff \& R. Oehrle (eds.), Language Sound Structure 287-298. Cambridge, MA: MIT Press.

. 1987. A Reduction and Spreading Theory of Voicing and Other Sound Effects. Ms., Universitat Autonoma de Barcelona. McCarthy, J. \& A. Prince. 1986. Prosodic Morphology. Ms., University of Massachusetts, Amherst \& Brandeis University. Myers, T. 1987. The Cognitive Representation of Speech. Amsterdam \& New York: North Holland Publishing Company. Prince, A. \& P. Smolensky. 1993. Optimality Theory: Constraint Interaction in Generative Grammar. Ms., Rutgers University \& University of Colorado.

Rajpurohit, B. 1983. Shina Phonetic Reader. Mysore: Central Institute of Indian Languages.

Rhee, S-C. 1998. Aspects of Release and Non Release in Phonology.

Ph.D Dissertation. University of Illinois, Urbana-Champaign.

Sagey, E. 1980. The Phrase Phonology of English and French. New York: Garland. . 1986. The Representation of Features and Relations in Non Linear Phonology. London: Garland.

Selkirk, E. 1982. Syllables. In H. van der Hulst \& N. Smith (eds.), The Structure of Phonological Representations 337-383. Dordrecht: Foris Publications.

Silverman, D. 1997. Phasing and Recoverability. New York \& London: Garland.

Steriade, D. 1997. Phonetics in Phonology: The Case of Laryngeal Neutralization. Ms., University of California, Los Angeles.

Tesar, B. \& P. Smolensky. 1998. Learnability in Optimality Theory. Lingusitic Inquiry 29, 229-268. 